UDC: 821.134.2(85).09-14 Vallejo C.

DOI: https://doi.org/10.18485/beoiber.2018.2.1.6

\author{
Ainhoa Segura Zariquiegui ${ }^{1}$ \\ Tianjin Foreign Studies University \\ China
}

\title{
MELANCOLÍA EN LA POESÍA ANDINA: “HIMNO A MANKO KAPAC»
}

\begin{abstract}
Resumen
La melancolía forma parte de la esencia del ser humano. Se ve proyectada en todas las áreas vitales de las mujeres y los hombres, especialmente, en el campo de la literatura. La melancolía occidental ha sido profusamente estudiada y analizada. Pero no ocurre lo mismo con la melancolía andina. Tras la conquista de América a manos de los españoles primero y los europeos después, el alma andina, ya de por sí melancólica, se fue sumiendo en una mayor tristeza. El objetivo de este trabajo es el de resaltar y dar cabida a la melancolía del alma andina y subrayar el aliento creativo del que manarán posteriores creaciones artísticas. La metodología a seguir es el uso de las herramientas que nos aporta la especialidad académica de la teoría de la Literatura y la Literatura Comparada. La elección del poema "Himno a Manko Kapac" es un homenaje al mundo indígena peruano. Esa melancolía intrínseca que dio lugar a este poema, muchos siglos después otorgará las alas al talento creador del genial poeta César Vallejo. La maravillosa poesía de este autor sigue la línea marcada por sus antecesores: los primeros poetas andinos autores de "Himno de Manko Kapac".
\end{abstract}

Palabras clave: cultura andina, poesía, indigenismo, Manko Kapac, melancolía.

\section{MELANCHOLY IN ANDEAN POETRY: “HYMN TO MANKO KAPAK»}

\begin{abstract}
Melancholy is part of the soul of the human being. It is projected in any vital women and men areas of the culture, especially in the field of literature. Western melancholy has been deeply studied and profusely analyzed, but the same has not happened with Andean melancholy. After the Conquest of America by the Spanish conquerors, the Andean soul fell in a lake of sadness. In this paper we try to show the brightness of the Andean heart. The selection of the poem "Hymn to Manko Kapac" is a homage to Peruvian indigenous culture. The intrinsic melancholy, many centuries later, will give wings to the creative talent of the brilliant poet César Vallejo. The wonderful poetry of this author continues the line shown by its predecessors: the first Andean poets who wrote "Hymn to Manko Kapac".
\end{abstract}

Key words: Andean culture, poetry, indigenism, Manko Kapac, melancholy.

1 ainhoaseguraza@hotmail.com 


\section{Sobre el concepto de melancolía}

La melancolía es una noción que ha recorrido la historia de la humanidad. Forma parte de la esencia del ser humano y por eso, desde los tiempos clásicos, ha sido señalada por poetas, artistas, médicos de distintas épocas. En tiempos presocráticos, la melancolía era un término que hacía referencia a enfermedades tanto mentales como físicas. De esta forma, se puede observar cómo el significado etimológico de la palabra se compone de melas $(\mu \varepsilon ́ \lambda \alpha \varsigma)$, término griego que significa negro y kholé ( $\chi 0 \lambda \eta \dot{)})$ que quiere decir humor o bilis. Como señala V. J. Domínguez García: "Ya en el Corpus Hipocraticum aparecen las palabras melancolía, melancólico y melancólicamente" (1991: 260). La medicina griega entendía que al ingerir los alimentos se producían sustancias que el cuerpo debía desechar, pero si no las expulsaba, se quedaban en su interior produciendo enfermedades. El humor negro o melancolía era la más dañina. Pero este concepto asociado en principio sólo a la enfermedad extendió su significado. Se puede observar ya esta ampliación en Sócrates, Platón y sobre todo Aristóteles. Estos filósofos dieron a la melancolía un carisma diferente: el ser melancólico era una persona que tenía, por naturaleza, una cantidad mayor de humor negro o melancolía en su ser, por lo tanto, era propenso a enfermedades mentales o físicas determinadas, pero, como reverso y compensación a esta faceta morbosa, poseía una conexión especial con las divinidades: "Aristóteles, con el texto de Problemas $X X X, 1$, - señala Rubén Peretó Rivas - introduce una precisión acerca de este tema. Dice: Todos los hombres excepcionales son melancólicos. Y cita varios casos: Heracles, Ajax y Belerofonte entre los guerreros; Empédocles, Sócrates y Platón entre los filósofos, y muchos más entre los poetas" (2012: 214). El ser melancólico era un ser excepcional tocado por los dioses, pero, a la vez, maldecido por ellos. En Fedro, Sócrates habla de la melancolía y la subdivide en dos tipos de locura: una primera, la locura como enfermedad humana, y una segunda, la locura como inspiración divina. A su vez, el filósofo divide esta inspiración divina en cuatro melancolías perteneciendo a cada cual una divinidad: la profética (Apolo), la mística (Dioniso), la poética (las Musas), y por último, la erótica o amorosa (Afrodita y Eros). Los dioses se relacionan con los humanos a través de estas cuatro fuerzas que se transforman en locura cuando habitan en exceso en el ser humano.

La tradición sobre la melancolía se extendió a lo largo de la cultura occidental y recorrió la historia medieval y renacentista. En ese momento, autores como Ficino volvieron a analizar los textos de autores clásicos y colocaron el concepto de la melancolía en el lugar donde lo dejaron: “Ficino - apunta Andrea Paul - une las herencias antiguas y medievales en búsqueda de una respuesta al temperamento melancólico" y hace que la unión entre el cosmos y Saturno se conecten con ideas plotinianas y árabes. Esta tradición ponía énfasis en la relación entre la melancolía con la creatividad (artística o de otro tipo) siguiendo los pasos de Aristóteles y de otros autores clásicos. El Renacimiento también fue el período histórico en el que se realizó la conquista de América. La melancolía occidental fue llevada por los navegantes españoles, e insertada 
en la sociedad indígena andina a través de la imposición de la cultura hispana. Por su parte, el mundo andino poseía su propia melancolía que expresaba en el arte creado por las mujeres y hombres de la sociedad precolombina. La unión de ambas creará una interesante síntesis.

\section{Poesía andina y melancolía}

La poesía andina es el producto artístico del imperio inca. El imperio Inca (denominado Tawantinsuyu en lengua quechua) fue uno de los grandes imperios de la era precolombina. El centro administrativo, político, militar y artístico se encontraba en Cuzco (Perú). La civilización inca brilló en el siglo XIII hasta que fue conquistado por los españoles en 1572. De 1438 a 1533, los incas incorporaron a sus propios territorios una gran porción del oeste de América del sur y anexionaron a Perú una gran parte de lo que hoy en día es Ecuador, el oeste y sur de Bolivia, el noroeste de Argentina, el norte y centro de Chile y una pequeña parte del sureste de Colombia. La lengua oficial era el quechua. Una parte importante de la esencia y la creatividad de la poesía modernista peruana está fundamentada en la melancolía andina. Esta poesía melancólica se fue desarrollando en el folclore hasta llegar a nuestros días. De hecho, la melancolía andina insufla de verdadero talento creador a la poesía modernista peruana posterior.

Los aspectos melancólicos precolombinos estaban incluidos en sociedad inca y eran manifestados a través de la expresión poética. Tras la conquista, se incorporó la melancolía occidental, la española más concretamente, que en esos años vivía su gran apogeo de los siglos de Oro. Estas dos melancolías realmente no convivieron (sólo en ciertos momentos) aunque existieron simultáneamente en el territorio virreinal. Mientras la poesía y su melancolía occidental se daban en la corte de Lima y centros urbanos, y tenía forma escrita, la poesía andina y su melancolía, se dispersaba a lo largo y ancho de los territorios de la sierra y la montaña, tenía un carácter comunitario y popular y era de transmisión oral. Por el poder preeminente de la metrópolis en el virreinato del Perú, los modelos literarios se tomaron de Occidente, lo que supuso una innovación mínima respecto a las posibilidades creativas de los peruanos. Mientras tanto, sin embargo, esta verdadera creatividad apegada a las raíces andinas perduró en el folclore, a pesar de que socialmente se encontraba relegada al tratarse de la creatividad de los vencidos. Esta situación se mantuvo durante todo el período colonial, pero ya en el período de la Independencia, por influencia del Romanticismo y del Volkgeist, algunos autores como Melgar comienzan a destacar las raíces andinas en la literatura. A pesar de cierto acercamiento a lo andino se le trata de modo pintoresco y sin llegar a profundizar para nada en la realidad india. 


\section{Expresión melancólica en la literatura andina}

La melancolía andina se expresó en los cantos y tradiciones heredadas de padres a hijos de forma oral. Es la base que forma y conforma la esencia de este pueblo: "Valcárcel a quien debemos tal vez la más cabal interpretación del alma autóctona - comenta Mariátegui - dice que la tristeza del indio no es sino nostalgia" (1928: 311). La tristeza indígena no es sino el síntoma del alma melancólica, y la nostalgia, no es sino ese alma melancólica retornando al ficticio pasado para regodearse en el recuerdo convertido en idealidad. Por muchos avatares que haya tenido la historia peruana, la cultura siempre está cimentada por la esencia del alma de lo autóctono. A pesar de la conquista, y de la imposición inhumana al indígena por parte de los españoles, y de la subyugación e infravaloración de lo andino, la esencia, la verdad, como dice Valdelomar, está en las raíces. Esa base que conforma el fondo está teñida, en el caso andino, de a melancolía andina. $Y$ ésta se une a la creatividad, sea escrita u oral. Por eso, se debe señalar que la literatura posterior tiene una gran deuda con el alma esencial y melancólica andina. $Y$ esto es así porque la concepción de la vida y la expresión literaria se la deben a ella. Veamos las palabras del crítico peruano Luis Alberto Sánchez: "El trasfondo de nuestra alma popular - y también de la ciencia popular - se apoya en aquel misterioso pasado aborigen $y$ que es de allí de donde nos viene, en forma de solecismos explícitos e implícitos, lo más auténtico y raigal de nuestra concepción de la vida y de nuestra expresión literaria" (1974: 22). Si la expresión literaria se une al alma popular andina, y el alma andina es melancólica, la expresión literaria será melancólica:

Eso, el Ollanta, los yaravíes y las leyendas que aún narran los viejos de la sierra; he allí la literatura incaica. Toda ella respira tristeza - afirma Luis Alberto Sánchez. No es, como se ha dicho, la melancolía serrana causada por las exacciones de los conquistadores es más antigua. Desde sus orígenes la raza llora en la voz de las quenas. Voz de una raza acostumbrada al vasallaje. Voz de una raza que vive de añoranzas. Narra las hazañas de los Ayar, canta el viaje triunfante de Huiracocha y su trágica desaparición, la derrota de Kon y la victoria de Pachacámac; pero ninguna exaltación va mezclada al relato. Hay siempre en él un imborrable dejo de tristeza (2000: 17-18).

No solamente el crítico literario Luis Alberto Sánchez, de tendencia aperturista en cuanto a lo indígena, piensa así. José de la Riva Agüero, de profunda raigambre hispánica, que enaltece sin medida el período colonial, tiene en cuenta la melancolía andina a la hora de hablar sobre la influencia de la literatura indígena en el período republicano en Perú: "Los indios tuvieron antes de la conquista, si no una verdadera literatura, por lo menos condiciones literarias definidas que han podido influir sobre los literatos de la república, ya por herencia, ya al inspirarse éstos en las costumbres y cantos populares de los indígenas. Aquellas condiciones son: la imaginación soñadora y 
nebulosa, la melancolía, el dolor íntimo y silencioso, una poesía amatoria impregnada de tristeza" (1962: 71). Fijémonos por un momento en las características que otorga José de la Riva Agüero a la literatura andina. Señala la 'imaginación soñadora', es decir la creatividad, la 'melancolía', 'el dolor íntimo y silencioso', y por último, el amor impregnado de tristeza. El propio José Gálvez, discípulo de José de la Riva Agüero, al analizar la posibilidad de la existencia de una genuina literatura nacional, considera que los poetas deben de tener en cuenta: "La melancolía del yaraví, la tristeza del indio" (1915: 75). Como se puede observar, los críticos modernistas como José de la Riva Agüero y Gálvez, así como los que llegan más tarde como Sánchez y tantos otros, confirman la existencia de un ethos melancólico en el alma andina.

\section{La melancolía andina en el poema "Himno a Manco Kapac"}

El poema "Himno de Manko Kapac" (Huaman 1988) nos brinda la oportunidad de analizar la melancolía intrínseca peruana en su fase más pura. Nos encontramos ante un poema místico, lo que da lugar a revisar la melancolía mística de la que hablara Sócrates. Para Sócrates, como se ha señalado anteriormente, existían cuatro clases de locuras inspiradoras que se podían dar en el ser humano. Cada locura tenía como origen una deidad: "Y en la locura divina distinguimos cuatro partes que asignamos a cuatro dioses, atribuyendo a Apolo la inspiración profética, a Dionisio la mística, a las Musas a su vez la poética, y la cuarta, la locura amorosa, que dijimos era la más excelsa, a Afrodita y a Eros" (1998: 248). La divinidad era la fuente y el poeta el receptáculo de los dioses. A Dionisio se le adjudica la mística, es decir, la poesía que pone en contacto al ser humano con la deidad. La locura melancólica es la que tiene como protagonista la relación entre la mujer y el hombre con la divinidad y es la que se va a observar en el poema. Manko Kapac fue el primer soberano inca $y$ era considerado como el maestro del mundo, surgido de las aguas que creó el cielo y la tierra. Esta poesía dedicada a su dios Wiracocha se conservó gracias a la tradición oral durante cuatro siglos hasta que fue registrada por el cronista indio Juan de Santacruz Pachacuti quien la recogió en su Relación de las antigüedades deste Reyno del Perú. Veamos el "Himno a Manko Kapac":

iAh Wiracocha, señor del origen!

Que esto sea hombre y esto mujer,

poderoso dueño del manantial sagrado,

maestro de sortilegios y misterios.

¿Dónde estás?

¿Es que no puedo verte?

¿Dónde está tu trono de gran señor?

¿Arriba, abajo, al través?

¡Respóndeme! Te lo ruego, 


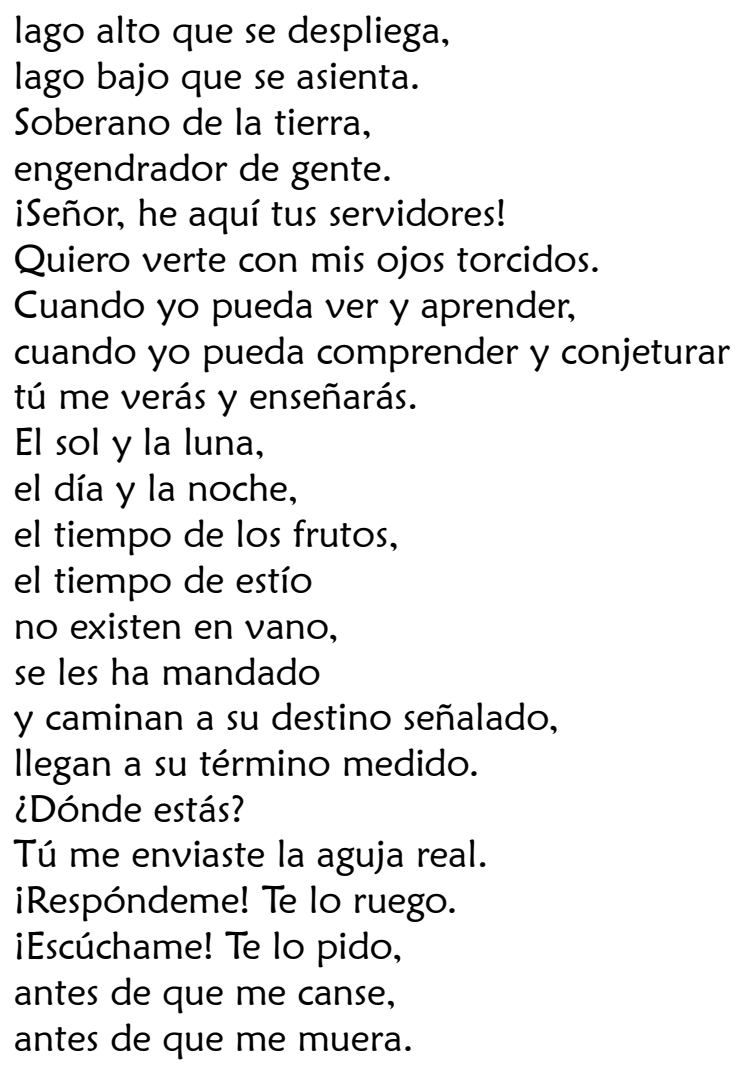

Ante la pérdida de la comunicación entre ser humano y divinidad, Manko Kapac suplica oír a su dios. Así es, en la composición se manifiesta un ser angustiado que llama anhelante, una y otra vez a Wiracocha. No entiende cómo puede abandonar un padre divino a su hijo mortal. La sensación de orfandad es total aquí, ya que falla el contacto con el creador, con el todopoderoso, motivo de postración y melancolía del gran Manko Kapac. Este monarca, el primer rey Inca, llevó a cabo, junto a su esposa Mama Ocllo, la misión de la fundación de la capital del Imperio en Cuzco. Tras surgir del lago Titicaca, Wiracocha les dio el báculo sagrado para elegir un lugar fértil. Ahora, muchos kilómetros han andado junto a su pueblo. Este es el contexto donde se sitúa el poema. Es el momento en el que Manko Kapac alza su mirada hacia Wiracocha para que le señale qué hacer, hacia dónde dirigirse con su pueblo para fundar el imperio inca. La atmósfera de tristeza y ansiedad queda expresada a través de versos de tierna emotividad, donde el soberano, implorante, se acerca con palabras sencillas pero llenas de angustia a su creador. Manko Kapac, ya anciano, trata de ponerse en contacto con el dios Wiracocha mediante la invocación. Todo el poema es una búsqueda de contacto que no tiene respuesta. El silencio de Wiracocha ante Manko Kapac deja al hombre-dios en un continuo aturdimiento. La melancolía se instala en su espíritu. Vuelve a sentir una profunda soledad y una orfandad que le sume en la perplejidad ante el mundo. 
Manko Kápac y su mujer Mama Ocllo surgieron del lago Titicaca. Wiracocha es un dios más abstracto que las antiguas huacas (lugares sagrados concretos como montañas, ríos, etc.). Algunos autores han señalado el mito de Afrodita, comparando el origen de la diosa con el significado de la palabra completa, ya que veían en esa sustancia fundamental, en la espuma y en el lago, el lugar de surgimiento. Ofrecemos otra comparación que resulta más interesante. Se trata de una comparación de marcado origen indígena (el principio de dualidad): la doble imagen del lago que aparece en el poema. Se observa claramente el principio de dualidad en ese equilibrio cósmico de calma y agitación entre las aguas de arriba y las de abajo: "lago alto que se despliega, / lago bajo que se asienta». También se produce otro ejemplo de dualidad al señalar Manko Kápac a Wiracocha como creador del hombre y de la mujer. Con armoniosa distribución, el dios no da preponderancia al sexo masculino, colocando a los dos géneros en un mismo nivel y estableciendo la diferenciación fundamental entre lo masculino y lo femenino. El poder generativo, tan cercano a la melancolía, está en manos de Wiracocha: "La visión del dios es pues la de un ente altamente productivo - afirma E. Bendezú - en constante creatividad y germinación, y por eso es mirado por el poeta como maestro de todos los sortilegios y misterios" (1986: 19). En la imagen que muestra Bendezú se encuentra una de las características de la melancolía divina, además de otorgar una locura o tristeza enfermizas, también Wiracocha es un dios que otorga la creatividad, ya que es un ser donde se condensa el halo creador y la geminación de ideas. La aseveración de E. Bendezú viene dada por la imagen del manantial que está conectada directamente con el agua que es un principio generador de vida. Encontramos la réplica del dios Wiracocha, creador y generador, en la figura de Manko Kapac, ya que, al igual que el dios, tiene (junto a su mujer Mama Ocllo), la tarea de crear un futuro imperio. La melancolía creadora es donada por el dios con el objetivo de utilizarla para crear un nuevo hogar para el pueblo andino, perdido en esos momentos en medio de la nada.

La religión andina e incaica requería realidades concretas como las huacas, es decir, realidades físicas, que se pudieran ver, tocar y oír. De ahí que el yo poético pregunte a Wiracocha dónde se encuentra físicamente: “¿Dónde estás? / ¿Es que no puedo verte? / ¿Dónde está tu trono de gran señor?", Manko Kapac comprende que el contacto sólo se puede dar entrando en ese espacio abstracto, poético y sagrado, como señala Sócrates, pero no puede pasar el límite que le impone lo físico. Vemos en este punto la expresión poética del principio de reciprocidad, puesto que: "El poeta que ha creado el espacio verbal del dios pide a su vez un signo verbal audible" (1986: 19). Manko Kapac ha creado una realidad a través de sus palabras y aguarda la plasmación material. Al aplicar el principio de reciprocidad (otro principio esencial de la sociedad andina), espera poder ver y oír al dios Wiracocha, pero este principio ha sido roto por el silencio. Ante la ruptura nace la melancolía: Manko Kapac, atónito, ruega y suplica a Wiracocha. Sus palabras pasan a implorar al dios engendrador de gente, colocándose él mismo como su servidor. La angustia, gradualmente, va elevándose hasta señalar que le mirará con 'los 
ojos torcidos', es decir, sin fijar la mirada directamente, tal y como hacían sus súbditos ante él. Tras la angustia, el Inca toma consciencia de la imposibilidad de contactar con el dios. Sabe que a través de los sentidos como la vista o el oído no llegará a traspasar los límites que señalan el comienzo del misterio. Su mirada no está preparada todavía para enfrentarse a tal situación. Manko Kapac es capaz de percibir, lo que muchos melancólicos llaman, el sol negro de la melancolía, lo que Durero señala, la angustia por ver que es imposible la adquisición mental del conocimiento total del mundo visible e invisible.

Wiracocha, más que un dios de carácter moral, es "una fuente de conocimiento racional y pragmático" (Bendezú 1986: 20). Fijémonos en la diferencia con el Cristianismo. En el Génesis se señala que los seres humanos tenían prohibido comer del fruto del árbol de la sabiduría. En cambio, Wiracocha es la donación de la comprensión y del entendimiento del mundo. Sólo cuando Manko Kapac 'pueda ver y aprender', es decir, cuando la mente se abra de una forma especial, será capaz de percibir la gran sabiduría. Resulta muy sugestivo observar la inversión que se da en este momento. Tras la sensación de angustia melancólica por el silencio del dios, el principio de reciprocidad roto se vuelve a rehacer. Ya que el hombre no puede ser cognoscente de lo divino, pide que sea Wiracocha el dios que se acerque al ser humano: "tú me verás y enseñarás", dice Manko Kapac. El soberano Inca será discípulo del dios y maestro de los demás andinos. Wiracocha enseñará los misterios de los astros y del comienzo y la finalización de los períodos. Resalta el principio de temporalidad cíclica (otro principio esencial de la sociedad indígena) puesto que el yo poético muestra distintas dualidades cíclicas como el día (sol) que da paso a la noche (luna) y así sucesivamente. Más representativos son los versos siguientes:

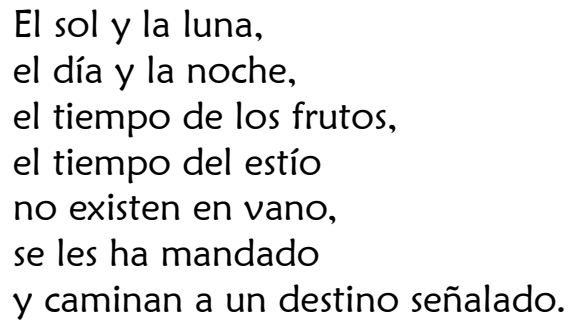

Cada elemento temporal tiene su lugar, el día, el sol, la noche y la luna. Igualmente, existe un tiempo para los frutos, es decir, para que nazcan, crezcan y sean recogidos. El yo poético señala el tiempo del estío, cuando ya ha sido recolectada la cosecha. Un período dará lugar al otro, de la misma forma que el día dará paso a la noche. Los ciclos tienen un tiempo limitado, como dice el poeta: "caminan a un destino señalado". Ese destino puede ser el Pachacuti, el momento en el que se cierran las edades o eras andinas que los cronistas diferenciaban por épocas más o menos benignas.

Manko Kapac, atónito de nuevo, al comprobar que ningún cambio se ha dado, todavía reitera la invocación: “¿Dónde estás?». El principio de reciprocidad se ha vuelto a 
romper. El soberano Inca tiene una relación misteriosa con el dios, Wiracocha le entregó el báculo real como prueba de poder de mando del Inca y de su estrecha relación. El dios entregó algo físico, y Manko Kapac le implora que él también tome forma física como correspondiente pago recíproco. El soberano inca parece desesperado, melancólicamente enloquecido:

iRespóndeme! Te lo ruego.

iEscúchame! Te lo pido, antes que me canse, antes que me muera.

\section{Conclusiones}

Las palabras se quedan flotando en el vacío. Retorna el silencio. Según E. Bendezú, Wiracocha no habla porque en vez de querer mostrar una sola voz del dios único y verdadero, como el cristiano, quiere que se oigan otras voces. Aparece aquí el principio de inclusión: "Frente al vasto espacio del dios único y verdadero que no admite otras deidades, el descarnado Wiracocha, acepta sin discusión todas las deidades que encuentra, las acoge en su espacio de formas frías, de abstracciones racionalistas, seguro que de las alturas y profundidades de sus lagos jamás será visto ni oído por el hombre ni podrá ser objeto de conflicto" (1986: 20). Los dioses andinos apelan a la armonía como fundamento básico de la convivencia entre seres humanos y divinidades. La melancolía es el nexo sagrado que hace realidad está unión. Gracias a la esencia divina, los hombres hablan con sus dioses, y viceversa.

La conclusión personal responde a la consecución de los objetivos de la demostración de la hipótesis de que la melancolía forma parte esencial del alma andina, que ha quedado observada a lo largo del desarrollo del análisis ofrecido. En la expresión del poema se observa la profundidad de su alma insuflada por el talento creador de la bilis negra andina que continuaremos viendo a lo largo de la historia de este país y que estallará en el Modernismo y Posmodernismo con el gran poeta peruano Vallejo.

\section{BIBLIOGRAFÍA}

Bendezú, Edmundo. La otra literatura peruana. México: Fondo de Cultura Económica, 1986. Impreso.

Domínguez, Vicente. “Sobre la melancolía en Hipócrates". Psicothema, 3/1 (1991): 259-267. Web. 
Gálvez, José. Posibilidad de una genuina literatura nacional. Lima: Casa Editora M. Moral, 1915. Impreso.

Huaman, Miguel Ángel, Poesía y utopía andina. Lima: DESCO, 1988. Impreso.

Mariátegui, José Carlos. 7 ensayos de interpretación de la realidad peruana. Lima: Amauta, 1928. Impreso.

Paul, Andrea María Noel. "El concepto de melancolía en Marsilio Ficino”. Eikasia, revista de filosofía, 57 (2014): 173-186. Web.

Peretó, Rubén. "Aristóteles y la melancolía. En torno a Problemata XXX, I". Contrastes. Revista Internacional de Filosofía, 17 (2012): 213-227. Web.

Platón. Fedro. Madrid: Alianza Editorial, 1998. Impreso.

Riva Agüero, José de la. Obras completas. Lima: Pontificia Universidad Católica del Perú, 1962. Impreso.

Sánchez, Luis Alberto. Introducción crítica a la literatura peruana. Lima: P. L. Villanueva Editor, 1974. Impreso.

—. Indianismo e indigenismo en la literatura peruana. Lima: Mosca Azul, 1990. Impreso.

- La literatura peruana. Lima: Instituto Víctor Raúl de la Torre, 2000. Impreso.

Tellenbach, H. Melancolía. Madrid: Morata, 1976. Impreso. 